\title{
ARAŞTIRMA / RESEARCH \\ Psoriazisin klinik şiddeti ile histopatolojik bulgular arasında ilişki var mıdır? klinikopatolojik bir çalışma
}

Is there a relationship between clinical severity of psoriasis and histopathological findings? a clinicopathological study

Figen Aslan (D)

Balıkesir Üniversitesi Tıp Fakültesi, Patoloji Anabilim Dalı, Balıkesir

\section{Cukurova Medical Journal 2019;44(2):319-324}

\begin{abstract}
Amaç: Bu çalışmada, histopatolojik bulgular ile psoriazisin klinik şiddeti arasında ilişki olup olmadığını araştırmayı amaçladık.

Gereç ve Yöntem: Bu retrospektif çalısmada, hem klinik hem de deri biyopsisi ile histopatolojik olarak psoriazis vulgaris tanısı konulan 51 olgu incelendi. Olgularin parafin bloklarından hazırlanan kesitleri mikroskobik olarak incelendi ve bulgular çeşitli histopatolojik özellikler açısından kaydedildi. Hastalığın şiddetini değerlendirmek için psoriazis alan şiddet indeksi (PASI) kullanıldı. PASI ile ilgili veriler hastaların tıbbi dosyalarından elde edildi. Hastalar daha sonra yüksek PASI skoru $(\geq 10)$ ve düşük PASI skoru $(<10)$ olanlar olarak gruplandırıldı.

Bulgular: Çalışmada, Psoriazis vulgaris olgularında (31 erkek, 20 kadın) 1.5: 1 olan erkek: kadın oranıla erkek baskınlığ1 görüldü. Psoriazisin aile öyküsü \% 29 hastada pozitifti. En s1k görülen histopatolojik özellikler: hiperkeratoz $\left(\%\right.$ 100), parakeratoz $\left(\begin{array}{lll}\% & 100\end{array}\right)$ (fokal parakeratoz ( $\% 23)$, konfluent parakeratoz $(\% 77))$, rete ridgelerin uzaması (\% 98) ve vasküler dilatasyon (\% 88) idi. Hastaların 30'unda (\% 58.8) düşük PASI skoru $(<10)$, 21 'inde (\% 41.2) yüksek PASI skoru $(\geq 10)$ vard1. Hastalığın şiddeti (PASI skoru) ile histopatolojik özelliklerin herhangi biri ile ilişki bulunmadı.

Sonuç: Psoriazisin karakteristik temel histopatolojik bulguları olmasına rağmen bu histopatolojik bulguların hiçbiri doğrudan hastalığın klinik şiddeti ile ilişkili değildir.
\end{abstract}

Key words: Psoriazis, histopatoloji, klinik şiddet, PASI
Öz

Purpose: In this study, we aimed to investigate whether there is a relationship between histopathologic findings and clinical severity of psoriasis.

Materials and Methods: In this retrospective study, 51 cases with psoriasis vulgaris diagnosed both clinically and histopathologically through a skin biopsy were analyzed. The sections prepared from the paraffin blocks of the cases were examined microscopically and the findings were recorded for various histopathological features. The psoriasis area severity index (PASI) used to assess the severity of the disease. Data regarding PASI were obtained from the patients'medical files. The patients were then grouped as those with high PASI score $(\geq 10)$ and low PASI score $(<10)$.

Results: The study showed male predominance with male:female ratio-1.5:1 of psoriasis vulgaris cases (31 males, 20 females). Family history of psoriasis was positive in $29 \%$ patients. The most prevalent histopathological features were hyperkeratosis $(100 \%)$, parakeratosis $(100 \%)$ (focal parakeratosis $(23 \%)$, confluent parakeratosis $(77 \%)$ ), elongation of rete ridges $(98 \%)$, and vascular dilatation $(88 \%)$. Out of the patients, $30(58.8 \%)$ had low PASI score $(<10)$,whereas $21(41.2 \%)$ had high PASI score $(\geq 10)$. There was no relationship between the severity of the disease (PASI score) and any of the histopathological features.

Conclusion: Although there are characteristic histopathological findings of psoriasis, none of these histopathological findings are directly related to the clinical severity of the disease.

Anahtar kelimeler: Psoriasis, histopathology, clinical severity, PASI

Yazışma Adresi/Address for Correspondence: Dr. Figen Aslan, Balıkesir Üniversitesi Tıp Fakültesi, Patoloji Anabilim Dalı, Balıkesir. E-mail: fgenaslan@gmail.com

Geliș tarihi/Received: 20.09.2018 Kabul tarihi/Accepted: 29.11.2018 Çevrimiçi yayın/Published online: 24.02.2019 


\section{GİRİ̧}

Psoriazis, anormal keratinosit hiperplazisi ile karakterize, ataklar ve remisyonlarla seyreden papüloskuamöz kronik inflamatuar deri hastalığıdır ${ }^{1}$. Hastalığın klinik tablosunun çok geniş olması nedeniyle tanıyı sadece klinik bulgulara göre koymak bazen zor olabilmektedir. Böyle durumlarda histopatoloji, psoriazis tanısını doğrulamak ve psoriazisi taklit eden klinik tabloları dışlamak için kaçınılmazdır ${ }^{2}$. Psoriazisin karakteristik histopatolojik bulgular1 arasinda psoriasiform epidermal hiperplazi, rete ridgelerde uzama, suprapapiller tabakada incelme, parakeratoz, hipogranüloz/agranüloz, Munro mikroabseleri (stratum korneumda nötrofil topluluğu), Kogoj’un spongioform püstülü (stratum spinozumda nötrofil topluluğu), dermal papillalarda genişlemiş ve kıvrıntılı kapillerler, dermisde perivasküler lenfositik infiltrasyon bulunmaktadır ${ }^{1,3}$.

Psoriazisin klinik şiddeti hastadan hastaya değişkinlik gösterir. Bazı durumlarda hastalığın şiddetini değerlendirmek için hastalığın klinik şiddeti ile histopatolojik bulgular arasındaki ilişkiyi araştırarak kantitatif olarak değerlendirmeye ihtiyaç vardır ${ }^{4}$. Biz burada psoriazisin en karakteristik histopatolojik bulgularını ve hastalığın klinik şiddeti ile histopatolojik bulguları arasında ilişki olup olmadığını araştırdık.

\section{GEREÇ VE YÖNTEM}

Balıkesir Üniversitesi Tıp Fakültesi Hastanesi'nde 2015-2018 y1llar1 arasında klinik ön tanıs1 psoriazis vulgaris olan ve punch biyopsi ile histopatolojik olarak psoriazis vulgaris tanısının konfirme edildiği 51 olgu çalışmaya alındı. Biyopsi yapılan olgular, 1 ay öncesine kadar topikal ya da sistemik tedavi görmemiş aktif plak lezyonları olan olgulardı. Olgulara ait parafin bloklardan Hematoksilen \& Eozin boyalı kesitler hazırlanarak psoriazis için karakteristik histopatolojik özellikler (hiperkeratoz, parakeratoz (fokal/konfluent), hipogranüloz, agranüloz, spongioz, Munro mikroabsesi, Kogoj'un spongioform püstülü, suprapapiller tabakada incelme, rete ridgelerde uzama, dermal papillalarda genişlemiş ve kıvrıntılı kapillerler, dermal lenfositik infiltrasyon (hafif/orta/şiddetli), dermal ödem) var/yok olarak değerlendirildi.

Hastalığın klinik şiddetini değerlendirmek için Psoriazis alan şiddet indeksi (PASI) kullanıld1 ${ }^{5}$. PASI hesaplanırken vücut; baş (b), gövde (g), üst ekstremite (u), alt ekstremite (a) olmak üzere 4 bölgeye ayrılmaktadır. Bu bölgelerdeki eritem (E), indürasyon (I) ve deskuamasyon (D) derecesi belirlenmektedir. Eritem (E), indürasyon (I) ve deskuamasyon (D) şiddeti, semptom yoksa 0 , hafif ise 1 , orta ise 2 , belirgin ise 3 , şiddetli ise 4 olmak üzere 0-4 arasında skorlanmaktadır (Tablo1).

Tablo 1. PASI hesaplamada vücudun 4 bölgesindeki plağın karakteristik lezyonlarına göre lezyonun şiddet indeksi

\begin{tabular}{|l|l|l|l|l|l|}
\hline Plakta karakteristik & $\begin{array}{l}\text { Lezyon şiddet } \\
\text { skoru }\end{array}$ & Baş & Gövde & $\begin{array}{l}\text { Üst } \\
\text { ekstremite }\end{array}$ & Alt ekstremite \\
\hline Eritem (E) & $\begin{array}{l}\text { 0= Lezyon yok } \\
\text { 1= Hafif } \\
\text { 2= Orta } \\
3=\text { Belirgin } \\
\text { 4= Şiddetli }\end{array}$ & & & & \\
\hline İndürasyon (I) & & & & \\
\hline \multirow{2}{*}{ Deskuamasyon (D) } & & & & \\
\hline
\end{tabular}

A: Lezyonların yaygınlığı için verilecek değer olup, lezyonların yaygınlığ1 \%10'un altında ise 1, \%10-29 ise 2, \%30-49 ise 3, \%50-69 ise 4,\%70-89 ise 5, \%90100 ise 6 olarak belirlenir. Son olarak PASI aşağıdaki formüle göre hesaplanmaktadır:

$0.1 \times(\mathrm{E} b+I b+D b) x A b+0.2 x(\mathrm{Eu}+I u+D u) \times A u+$ $0.3 \times(\mathrm{Eg}+\mathrm{Ig}+\mathrm{Dg}) \times A g+0.4 \times(\mathrm{E} a+\mathrm{I} a+D a) \times A a$.

Çalışmamızda aynı dermatolog tarafindan değerlendirilen PASI skorları hastaların klinik dosyalarından kaydedildi. PASI skorlarına göre olgular, yüksek PASI skoru olanlar $(\geq 10)$ ve düşük PASI skoru olanlar $(<10)$ olarak iki gruba ayrildı ${ }^{6}$.
Histopatolojik parametrelerle bu iki grup arasındaki ilişki istatistiksel olarak araştırıldı.

\section{İstatistiksel analiz}

İstatistiksel çalışma SPSS for Windows 22.0 istatistik paket programı yardımıla yapıldı. Parametrik değişkenlerde Pearson Ki-Kare testi, nonparametrik değişkenlerde Fisher's Exact test kullanıldı. Karşılaştırmalarda $\quad \mathrm{P}<0.05$ anlamlı olarak kabul edildi. 


\section{BULGULAR}

Çalıșmamıza alınan 51 psoriazis olgusunun 31'i erkek (\%60.8), 20'si kadındı (\%39.2). Olgularımızın yaşı 20 ile 70 yaş aralı̆̆ında olup yaş ortalaması 45.19 yıldı (45.19 +14.79$)$. Aile hikayesi olgularımızın \%29'unda vardı. Olgularımızda hastalığın başlangıç yaşı ortalaması 33.41 idi. Histopatolojik bulgulardan hiperkeratoz (\%100), parakeratoz (\%100 [fokal parakeratoz (\%23), konfluent parakeratoz (\%77)]), rete ridgelerde uzama (\%98) ve vasküler dilatasyon (\%88) biyopsilerde en fazla karşılaşılan bulgulardandı. Olgularımızın biyopsilerindeki histopatolojik özellikler Tablo 2'de ve Şekil 1-2'de gösterilmektedir.

Düşük PASI skorlu $(<10)$ olgularımızın sayısı 30 $(\% 58.8) \quad$ iken yüksek PASI skorlu $(\geq 10)$ olgularımızın sayısı $21(\% 41.2)$ idi. Hastalığın klinik şiddeti (PASI skor) ile histopatolojik bulguların hiçbiri ile istatistiksel olarak anlamlı ilișki görülmedi (P>0.05). Düşük PASI skorlu $(<10)$ ve yüksek PASI skorlu $(\geq 10)$ gruplar ile histopatolojik bulgular arasındaki ilişki Tablo 3'te gösterilmektedir.

Tablo 2. Olgulardaki histopatolojik özelliklerin sıklığ1

\begin{tabular}{|l|c|c|}
\hline & $\mathbf{n}$ & $\mathbf{\%}$ \\
\hline Hiperkeratoz & $51 / 51$ & 100.0 \\
\hline Parakeratoz & & 23.5 \\
Fokal parakeratoz & $12 / 51$ & 76.5 \\
Konfluent parakeratoz & $39 / 51$ & 49.0 \\
\hline Hipogranüloz & $25 / 51$ & 50.9 \\
\hline Agranüloz & $26 / 51$ & 29.4 \\
\hline Spongioz & $15 / 51$ & 54.9 \\
\hline Munro mikroabseleri & $28 / 51$ & 7.8 \\
\hline Kogoj'un spongioform püstülü & $4 / 51$ & 76.5 \\
\hline Suprapapiller tabakada incelme & $39 / 51$ & 98.0 \\
\hline Rete ridgelerde uzama & $50 / 51$ & 88.2 \\
\hline Dermal papillalarda genişlemiş ve kivrıntılı kapillerler & $45 / 51$ & 13.7 \\
\hline Dermal lenfositik infiltrasyon & & 62.7 \\
Hafif derecede & $7 / 51$ & 23.5 \\
Orta derecede & $32 / 51$ & 27.5 \\
Şiddetli & $12 / 51$ & \\
\hline Dermal ödem & $14 / 51$ & \\
\hline
\end{tabular}

Tablo 3. PASI ve histopatolojik özellikler arasındaki ilişki

\begin{tabular}{|c|c|c|c|}
\hline Histopatolojik özellikler & $\begin{array}{l}\text { Düşük PASI skorlu } \\
\text { olguların sayısı (\%) }\end{array}$ & $\begin{array}{l}\text { Yüksek PASI skorlu } \\
\text { olguların sayısı (\%) }\end{array}$ & $\mathbf{P}$ \\
\hline Hiperkeratoz & $30 / 30(100.0)$ & $21 / 21(100.0)$ & - \\
\hline $\begin{array}{l}\text { Parakeratoz } \\
\text { Fokal parakeratoz } \\
\text { Konfluent parakeratoz }\end{array}$ & $\begin{array}{l}6 / 30(20.0) \\
24 / 30(80.0)\end{array}$ & $\begin{array}{ll}6 / 21 & (28.6) \\
15 / 21 & (71.4)\end{array}$ & $\begin{array}{l}0.478 \\
0.478\end{array}$ \\
\hline Hipogranüloz & $14 / 30(46.7)$ & $9 / 21 \quad(42.9)$ & 0.788 \\
\hline Agranüloz & $13 / 30(43.3)$ & $11 / 21 \quad(52.4)$ & 0.524 \\
\hline Spongioz & $7 / 30 \quad(23.3)$ & $8 / 21 \quad(38.1)$ & 0.255 \\
\hline Munro mikroabseleri & $18 / 30(60.0)$ & $10 / 21 \quad(47.6)$ & 0.382 \\
\hline Kogoj’un spongioform püstülü & $2 / 30 \quad(6.7)$ & $2 / 21 \quad(9.5)$ & 0.709 \\
\hline Suprapapiller tabakada incelme & $23 / 30 \quad(76.7)$ & $16 / 21 \quad(76.2)$ & 0.969 \\
\hline Rete ridgelerde uzama & $30 / 30 \quad(100.0)$ & $20 / 21 \quad(95.2)$ & 0.227 \\
\hline $\begin{array}{l}\text { Dermal papillalarda genişlemiş ve } \\
\text { kıvrıntılı kapillerler }\end{array}$ & $26 / 30 \quad(86.7)$ & $19 / 21(90.5)$ & 0.678 \\
\hline $\begin{array}{l}\text { Dermal lenfosittik infiltration } \\
\text { Hafif derecede } \\
\text { Orta derecede } \\
\text { Siddetli }\end{array}$ & $\begin{array}{ll}2 / 30 & (6.7) \\
22 / 30 & (73.3) \\
6 / 30 & (20.0)\end{array}$ & $\begin{array}{ll}5 / 21 & (23.8) \\
10 / 21 & (47.6) \\
6 / 21 & (28.6)\end{array}$ & $\begin{array}{l}0.080 \\
0.227 \\
0.478\end{array}$ \\
\hline Dermal ödem & $7 / 30(23.3)$ & $7 / 21 \quad(33.3)$ & 0.431 \\
\hline
\end{tabular}




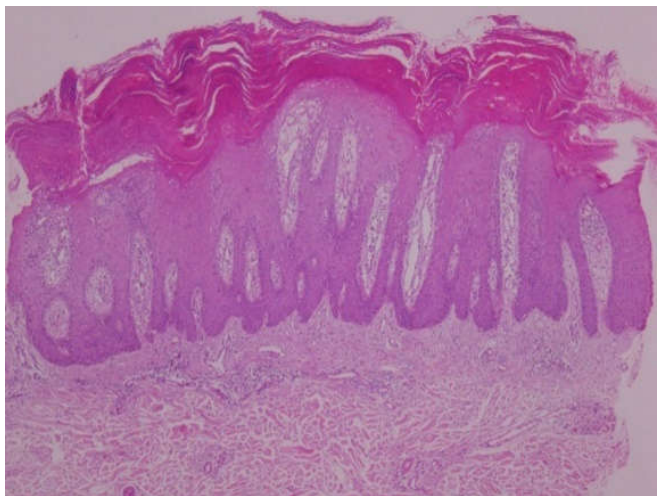

Şekil 1. Psoriazis vulgaris olgusuna ait deri punch biyopsi (H\&E,x40).

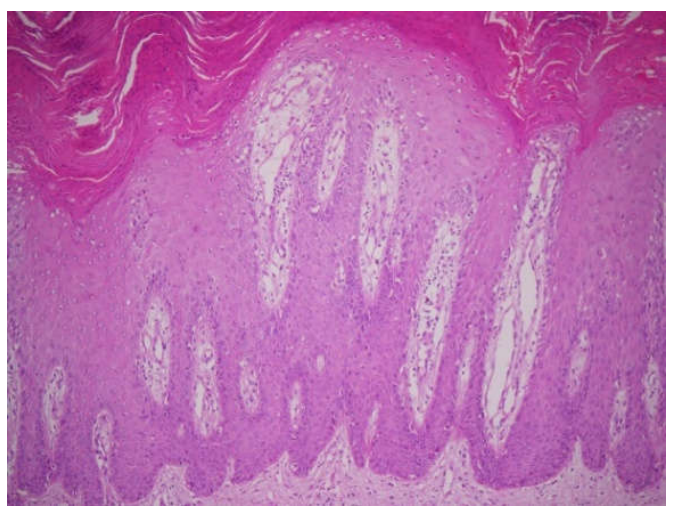

Şekil 2. Şekil 1'in yakın büyütmesinde epidermisde hiperkeratoz, konfluent parakeratoz, agranüloz, stratum korneumda nötrofil topluluklari, suprapapiller tabakada incelme, rete ridgelerde uzama, dermal papillalarda genişlemiş ve kıvrıntılı kapillerler, dermisde hafif lenfositik infiltrasyon (H\&E,x100).

\section{TARTIŞMA}

Psoriazis, dünya nüfusunun yaklaşık \%1-3’ünde görülen derinin tekrarlarla giden inflamatuar, proliferatif hastalığıdır ${ }^{7}$. Psoriazisin çeşitli dermatolojik hastalıkları taklit eden ve histopatolojik olarak ayırıcı tanısını gerektiren çeşitli klinik tabloları vardır. Psoriazis; guttat, plak, püstüler ve eritrodermik tip olmak üzere farklı klinik subtiplere ayrilır ${ }^{4}$. Plak psoriazis (psoriazis vulgaris), tüm psoriazis olgularının yaklaşı1k \% 80-90'ını oluşturur ${ }^{8}$.

Psoriazisin etyolojisi multifaktöriyel olup bunların arasında başlica çevresel faktörler ve genetik gösterilmektedir. Genetik olarak hastalığın gelişiminden HLA-Cw6 isimli gen sorumlu tutulmaktadır 9 . Hastalığın erken başlangıcı ile aile hikayesi arasında yakın bir ilişki vardır. Olgularımızda hastalığın başlangıç yaşı ortalaması 33.41 idi. Bu durum Stuart'ın teorisi olan hastalığın başlangıç yaşının 40 yaşının altında olmasının HLACw6 geninin herediter etkisi ile ilişkili olmasıyla açıklanabilir ${ }^{10}$.

Çalışmamızda olgularımız erkek üstünlüklü (\%60.78) olup erkek: kadın oranı 1.5:1 idi. Hastalığın görülmesinde cinsiyet ayrımı ile ilgili net sonuç bulunmamaktadır. Bazı çalışmalarda erkek üstünlüğü görülürken ${ }^{1,4,5,11}$ bazı çalışmalarda da kadın üstünlüğü vardır ${ }^{6,9,12}$.

Histopatolojik inceleme psoriazis klinik tanısını doğrulayacak olan tek yöntemdir. Histopatolojik olarak karakteristik temel bulgulara sahiptir. Histopatolojik tanı bu temel bulguların detaylı bir şekilde incelenmesiyle yapilır ${ }^{4}$ Olgularımızda hiperkeratoz (\%100), parakeratoz (\%100 [fokal parakeratoz (\%23), konfluent parakeratoz (\%77)]), dermal lenfositik infiltrasyon (\%100), rete ridgelerde uzama (\%98) ve dermal papillalarda kivrintilı ve genişlemiş kapillerler (\%88) en fazla karşılaşılan temel bulgulardandi. $\mathrm{Bu}$ bulgulardan sonra suprapapiller tabakada incelme (\%76), Munro mikroabseleri (\%54), agranüloz ( $\% 50)$, hipogranüloz $(\% 49)$, spongioz (\%29) ve dermal ödem (\%27) giderek azalan oranda karşılaştığımız bulgulardandı.

Epidermisde parakeratoz ve granüler tabaka arasında ters ilişki vardır. Parakeratozun belirgin olduğu durumlarda hipogranüloz ya da agranüloz görülür ${ }^{3}$. Çalışmamızda olgularımızın \%100'ünde görülen parakeratoza \%99 oranda hipogranüloz ya da agranüloz eşlik etmektedir. Psoriazisin klinik bulgularından olan skuamların mekanik olarak kaldırılmasından sonra küçük kanama odaklarının oluşması olarak bilinen Auspitz belirtisinin nedeni stratum granülozumun incelmesi yanında dermal papillalarda yeni oluşmuş kıvrıntılı, dilate ve fragil kan damarlarıdır?. Olgularımızın \%88'inde gördüğümüz dermal papillalarda kıvrıntılı ve genişlemiş kapillerler Hermawan ve ark.' $1 n^{9}$ çalışmasinda $\% 75$, Mehta ve ark.'1n ${ }^{7}$ çalışmasında \%86.9 oranında görüldü. Kogoj'un spongioform püstülü en az oranda (\%7) gördüğ̈umüz histopatolojik bulguydu. Munro mikroabseleri ve Kogojun spongioform püstülü psoriazisin patognomonik bulgularıdır ancak bunlar daha az 
karșılașılan bulgulardandır. Munro mikroabselerinin beklenildiği kadar sık görülmemesinin nedeni stratum korneumdaki parçalanma ve dökülmeler olabilir. Ayrıca mikroabseleri görebilmek için bazen çoklu kesitlere ihtiyaç vardır ${ }^{3}$. Bazı çalışmalarda bu bulgular bizim sonuçlarımıza göre daha yüksek oranlarda görülürken ${ }^{1,4}$ bazı çalışmalarda da daha düşük oranlardadır ${ }^{9,11}$.

Psoriazisin klasik histopatolojik bulguları olmasina rağmen histopatolojik bulgular hastalığın klinik özelliğine göre değişkenlik göstermektedir. Hastalığın klinik özellikleri ya da şiddeti ve histopatolojik bulguları üzerine az sayıda çalışma bulunmaktadır $\mathrm{r}^{3,4,9,13,14}$. Psoriazisin klinik şiddetini ortaya koymak için çeșitli klinik skorlama sistemleri kullanılmaktadır. Bunların arasında en sık kullanılan klinik skorlama sistemi, psoriazis alan şiddet indeksi (PASI) 'dir. PASI uluslararası klinik çalışmalarda da psoriazis şiddetini derecelendirmek için en $\mathrm{s} 1 \mathrm{k}$ kullanılan yöntemdir $3,5,7,12,14,15$. Psoriazisin hafif ve orta şiddette veya şiddetli olduğunu niteleyen tam olarak kabul görmüş bir tanımı olmadığından bazı çalışmalarda plak psoriazisinin şiddeti PASI skorlarına göre PASI $\geq 10^{16}$ ya da $\mathrm{PASI}>10^{15,17}$ olarak tanımlanmıştır. Çalışmamızda da psoriazis olgularımızı klinik şiddetlerine göre $\mathrm{PASI}<10$ ve PASI $\geq 10$ olmak üzere 2 gruba ayırdık.

Psoriazisin klinik tipleri ile tedavi öncesi ve tedavi sonrası klasik histopatolojik özellikleri üzerine yapılmış çeşitli çalışmalar bulunmaktadır ${ }^{3,4}$. Puri N. ve ark.'in psoriazis vulgaris olgulariyla yaptığ1 çalışmada epidermal değișikliklerde tedaviden önce ve sonra istatistiksel olarak anlamlı fark görülürken dermal değişikliklerde istatistiksel fark görülmemiştir ${ }^{3}$. Ayrıca Kim BY. ve ark., histopatolojik kantitatif grade'leme sisteminin psoriazis şiddetini değerlendirmede yeni bir yöntem olarak kullanılabileceği hipotezleri üzerine bir çalışma yapmışlardır. Yazarlar psoriazisin 4 klinik tipi (guttat, papüler, küçük plak, büyük plak) ile 10 histopatolojik bulgu (rete ridgelerde uzama, dermal papillalarda uzama, dermal ödem, suprapapillar incelme, Kogoj'un spongioform püstülü, granüler tabaka yokluğu, parakeratoz, Munro mikroabseleri, inflamatuar hücre infiltrasyonu,vasküler dilatasyon) arasındaki ilişkiyi araştırdığında Munro mikroabseleri, Kogoj'un spongioform püstülü ve inflamatuar hücre infiltrasyonunu içeren 3 histopatolojik bulgu dişında diğer histopatolojik bulgular ile hastalığın klinik tipleri arasında istatistiksel olarak anlamlı fark görmüşlerdir. Ancak bu histopatolojik bulgular ile yapılan kantiatif histopatolojik gradeleme sistemi ile psoriazis şiddet indeksi (PSI) arasında istatistiksel olarak anlamlı fark bulunmamıştır ${ }^{4}$. PASI ile histopatolojik bulgular arasındaki ilişkiyi değerlendirmek için yaptığımız şimdiki çalışmada da bu çalışmaya paralel olarak PASI ile histopatolojik bulguların hiçbiri arasında istatistiksel olarak anlamlı ilişki görülmedi ( $\mathrm{P}>0.05)$. Histopatolojik incelemede bulgular psoriazisin klinik tiplerine göre ve örnek alınan lezyonun erken veya geç evrede bir lezyon olmasına göre de çeşitlilik göstermektedir. Çalışmamız psoriazis vulgarisin histopatolojik özelliklerini inceleyen retrospektif bir çalısma olduğundan histopatolojik bulgular ve psoriazisin klinik tipleri arasındaki ilişki belirlenememiştir. $\quad \mathrm{Bu}$ klinik özelliklerin değerlendirileceği prospektif çalışmalarda, histopatolojik bulgular ile klinik bulgular arasındaki ilişkiyi daha ayrıntılı değerlendirmek mümkün olacaktır.

Sonuç olarak çalışmamıza göre psoriazisin karakteristik temel histopatolojik bulguları olmasina rağmen bu histopatolojik bulguların hiçbiri doğrudan tek başına hastalığın klinik şiddeti ile ilişkili değildir. Ancak psoriazisin farklı klinik tiplerini içeren daha geniş serili prospektif çalışmalarda, histopatolojik bulguların birlikte değerlendirilebileceği bir skorlama sistemi oluşturularak hastalığın klinik gidişi ile ilgili fikir sahibi olmak mümkün olabileceği gibi tedavi için de yön verilebilir.

Yazar Katkıları: Çalı̧̧ma konsepti/Tasarımı: FA; Veri toplama: FA; Veri analizi ve yorumlama: FA; Yazı taslağı: FA; İçeriğin eleştirel incelenmesi: FA; Son onay ve sorumluluk: FA; Teknik ve malzeme desteği: FA; Süpervizyon: FA; Fon sağlama (mevcut ise): yok. Bilgilendirilmiş Onam: Katılımcılardan vazılı onam alınmıștır. Hakem Değerlendirmesi: Dış bağımsız.

Çıkar Çatışması: Yazarlar çıkar çatışması beyan etmemişlerdir. Finansal Destek: Yazarlar finansal destek beyan etmemișlerdir.

Author Contributions: Concept/Desion : FA; Data acquisition: FA Data analysis and interpretation: FA; Drafting manuscript: FA; Critical revision of manuscript: FA; Final approval and accountability: FA; Technical or material support: FA; Supervision: FA; Securing funding (if available): $\mathrm{n} / \mathrm{a}$.

Informed Consent: Written consent was obtained from the participants.

Peer-review: Externally peer-reviewed.

Conflict of Interest: Authors declared no conflict of interest.

Financial Disclosure: Authors declared no financial support

\section{KAYNAKLAR}

1. Bai S, Sowmya S. Histopathologic diagnostic parameters of psoriasis; a clinicopathological study. Int J Res Med Sci. 2016;4:1915-20.

2. Kaddu S, Hödl S, Soyer HP. Histopathologic 
spectrum of psoriasis. Acta Dermatovenerol APA. 1999;8:94-100.

3. Puri N, Mahajan BB, Kaur S Clinicohistopathological correlation of psoriasis in acute exacerbation. Open Access Sci Rep. 2012;1:455.

4. Kim BY, Choi JV, Kim BR, Youn SW. Histopathological findings are associated with the clinical types of psoriasis but not with the corresponding lesional psoriasis severity index. Ann Dermatol. 2015;27:26-31.

5. Langley RG, Ellis CN. Evaluating psoriasis with psoriasis area and severity index, psoriasis global assessment, and lattice system physician's global assessment. J Am Acad Dermatol. 2004;51:563-9.

6. Chau T, Parsi KK, OgaWa T, Kiuru M, Konia T, Li CS, et al. Psoriasis or not? Review of 51 clinically confirmed cases reveals an expanded histopathologic spectrum of psoriasis. J Cutan Pathol. 2017;44:101826.

7. Mehta S, Singal A, Singh N, Bhattacharya SN. A study of clinicohistopathological correlation in patients of psoriasis and psoriasiform dermatitis. Indian J Dermatol Venereol Leprol. 2009;75:100.

8. Rosa G, Fernandez AP, Schneider S, Billings SD. Eosinophils are rare in biopsy specimens of psoriasis vulgaris. J cutaneous pathology. 2017;44:1027-32.

9. Hermawan WC, Hermin A, Dendi S. Clinical and histopathological characteristics of psoriasis in Dr. Hasan Sadikin General Hospital Bandung from 2009 to 2013. Althea Medical Journal. 2017;3:556-61.
10. Stuart P, Malick F, Nair RP, Henseler T, Lim HW, JenisCh S, et al. Analysis of phenotypic variation in psoriasis as a function of age at onset and family history. Arch Dermatol Res. 2002;294:207-13.

11. Raghuveer C, Doddarangaiah RS, Nadiga R. A Clinico-histopathological Study of Psoriasis. Int J Sc1 Study. 2015;3:176-9.

12. Silva MF, Fortes MR, Miot LD, Marques SA. Psoriasis: correlation between severity index (PASI) and quality of life index (DLQI) in patients assessed before and after systemic treatment. An Bras Dermatol. 2013;88:760-3.

13. Murphy M, Kerr P, Grant-Kels JM. The histopathologic spectrum of psoriasis. Clin Dermatol. 2007;25:524-8.

14. Karumbaiah KP, Anjum A, Danger K, Mallikarjun M, Kariappa TM, Paramesh. A Clinicopathological study of Psoriasis. Sch J App Med Sci. 2014;2:298302.

15. Oji V, Luger TA. The skin in psoriasis: assessment and challenges. Clin Exp Rheumatol. 2015;33:14-9.

16. Norlin JM, Calara PS, Persson U, Schmitt-Egenolf M. Real-world outcomes in 2646 psoriasis patients: one in five has $\mathrm{PASI} \geq 10$ and/or DLQI $\geq 10$ under ongoing systemic therapy. J Dermatol Treat. 2017;28:500-4.

17. Mrowietz U, Kragballe K, Reich K, Spuls P, Griffiths CEM, Nast A. et al. Definition of treatment goals for moderate to severe psoriasis: a European consensus. Arch Dermatol Res. 2011;303:1-10. 